\title{
APROVEITAMENTO DOS DIREITOS DA PERSONALIDADE E PREVENÇÃO DE CONFLITOS: A IMPORTÂNCIA DO CONSENTIMENTO E SEUS LIMITES
}

\author{
Julio Cesar Franceschet* ${ }^{1}$ \\ Guilherme Galhardo Antonietto** \\ Alexandra Moro Caricilli Botasso***
}

\section{Resumo}

Os novos contornos conferidos aos direitos da personalidade trazem número expressivo de negócios jurídicos e obtenção de vantagens econômicas decorrentes de sua inserção nas relações negociais. Nesse contexto, discute-se a importância do consentimento esclarecido para a prevenção e gestão dos conflitos decorrentes do aproveitamento econômico dos direitos da personalidade. Portanto, o objetivo é analisar se e quais negócios jurídicos dessa espécie devem ser vedados pelo ordenamento jurídico, impedindo-se a exposição de sujeitos a situações degradantes, e encontrar o equilíbrio entre as dimensões moral e patrimonial dos direitos da personalidade e seu papel na prevenção e gestão de conflitos.

Palavras-chave: Direito da personalidade; Vantagens econômicas; Tutela positiva; Direitos privados; Gestão e Prevenção de Conflitos

\section{THE EXPLOITATION OF PERSONALITY RIGHTS AND CONFLICT PREVENTION: THE IMPORTANCE OF CONSENT AND ITS LIMITATIONS}

\begin{abstract}
The new outlines that personality rights have acquired invoke a significant number of legal transactions and gain of economic advantages, resulting from its insertion in business relations. It is in this context that the importance of informed consent for managing conflicts resulting from the economic exploitation of personality rights is discussed. Therefore, the aim is to analyze if and which of these transactions should be forbidden by our legal system to avoid exposing people to irregular and degrading situations and to find the balance between moral and patrimonial dimensions of personality rights and its part in managing and preventing conflicts.
\end{abstract}

\footnotetext{
1 *Doutor em Direito Civil pela Universidade de São Paulo, Mestre em Direito Civil pela Universidade do Estado do Rio de Janeiro, professor no curso de graduação em Direito e no programa de Mestrado Profissional em Direito e Gestão de Conflitos da Universidade de Araraquara. E-mail: jcfranceschet@uniara.edu.br. Endereço postal: Rua Tiradentes, 519, Centro, Ibitinga/SP, CEP 14940-000.

**Mestre em Direito pela Universidade de Araraquara, especialista em Direito Civil pela PUC/MG, graduado em Direito pela USP de Ribeirão Preto. E-mail: guilherme@galhardoadvocacia.com.br. Orcid n. https://orcid.org/0000-0001-9701-1555. Endereço postal: Av. São Paulo, 735, Centro, Araraquara/SP, CEP 14801-060.

*** Mestranda no Programa de Pós-Graduação em Direito e Gestão de Conflitos da UNIARA, especialista em Direito Processual Civil e em Direito Penal e Processual Penal, advogada, mediadora pelo Tribunal de Justiça de Minas Gerais e facilitadora de círculos restaurativos. E-mail: alexandramoro@yahoo.com.br. Orcid n. https://orcid.org/0000-0002-6569-8011. Endereço postal: Rua Argentina, 448, ap. 901, bairro Girassol, Americana/SP, CEP 13465-690.
} 
Keywords: Personality rights; Economic advantages; Positive protection; Private rights; Conflict management and prevention

\section{INTRODUÇÃO}

O desenvolvimento dos meios de comunicação, da tecnologia e, em especial, a maior compreensão da pessoa sobre seu próprio corpo e os atributos de sua personalidade têm levado à efetiva fruição dos direitos da personalidade, elevando-os à categoria de liberdades positivas. Inicialmente tutelados sob o aspecto negativo, os direitos da personalidade passam a ser exercidos de forma positiva, tornando-se, com frequência, objeto de negócios jurídicos.

Nos dias atuais, os direitos da personalidade revelam dupla dimensão: uma negativa ou defensiva, dedicada à reparação dos danos decorrentes da injusta violação ou a cessação da ameaça de lesão; e outra positiva, caracterizada pelo aproveitamento, sobretudo econômico, dos bens que integram a personalidade.

A tutela positiva conduz a um número expressivo de negócios jurídicos que têm por objeto direitos da personalidade. A título de exemplo, podem ser citados os contratos de cessão de imagem e de voz, exploração de privacidade em realities shows, cessão de direitos autorais, conteúdos em mídias digitais e redes sociais, entre outros.

Aquela qualificação extrapatrimonial conferida inicialmente aos direitos da personalidade parece não mais coadunar-se com o seu aproveitamento. Isso porque, o cenário atual confere novos contornos aos direitos da personalidade, permitindo, assim, ao seu titular a obtenção de vantagens econômicas decorrentes da sua inserção em relações negociais.

A propósito do tema, António Menezes Cordeiro defende que os direitos privados da personalidade "representam, como quaisquer outros direitos subjetivos, posições de liberdade, reconhecidas ao seu beneficiário. Nessa qualidade, eles implicam "disponibilidade",2 (CORDEIRO, 2004, p. 105-106), ainda que relativa, coadunando-se com o aproveitamento econômico livre e consentido.

\footnotetext{
2 “As grandes restrições advêm da não-patrimonialidade de vários deles e da inerência de todos: o Direito poderá consentir em limitações graciosas e temporárias: mas não na sua troca por dinheiro ou numa alienação definitiva. Quanto à graciosidade, será o caso dos direitos do círculo biológico e do círculo moral. Todavia, apenas caso a caso será possível formular um juízo definitivo". (CORDEIRO, 2004, p. 105-106). No tocante à temporalidade: o artigo $81 .^{\circ}$ fixa numa regra de livre revogabilidade, [...] "ainda que com obrigação de indemnizar os prejuízos causados às legítimas expectativas da outra parte" (Ibid., p. 115).
} 
Vê-se, assim, que, a despeito do disposto no Código Civil Brasileiro, os direitos da personalidade são compatíveis com limitações decorrentes da vontade, voltadas ao seu efetivo aproveitamento, especialmente no contexto das relações negociais.

Nesta ordem de ideias, aspecto fundamental da tutela positiva dos direitos da personalidade diz respeito ao seu aproveitamento econômico. Isso porque alguns bens da personalidade, em decorrência do seu aproveitamento, passaram a ter valoração econômica. É o que ocorre, por exemplo, com a cessão do direito à imagem e com a exploração econômica da privacidade em alguns programas veiculados em televisão e internet.

Vale destacar, neste ponto, que, em época recente, a discussão em torno das biografias não autorizadas revelou muito mais do que elementos morais da personalidade; estavam, e ainda estão, em causa também fatores econômicos, relativos ao aproveitamento dos bens que integram a personalidade do biografado.

Nesse novo contexto, revela-se indispensável compreender o papel da vontade no aproveitamento dos direitos da personalidade. Com efeito, dado o fundamento ético que permeia os direitos da personalidade, é preciso estabelecer limites quanto ao seu aproveitamento, sendo certo que os negócios jurídicos que têm por objeto bens da personalidade sujeitam-se a regime especial quanto à execução das obrigações ajustadas e, ainda, quanto à extinção do vínculo obrigacional.

É preciso, pois, revisitar os direitos da personalidade a fim de compreender sua dimensão patrimonial e estabelecer limites à autonomia da vontade no que diz respeito ao seu aproveitamento, notadamente econômico, como forma de prevenção e gestão de conflitos.

Assim, com rigor científico e atentos aos estudos nacionais e estrangeiros a que tivemos acesso durante a pesquisa buscamos, como objetivo geral, analisar o papel do consentimento no aproveitamento dos direitos da personalidade; já, em específico, procuramos identificar os contornos e as características do consentimento na gestão e prevenção de conflitos decorrentes desse aproveitamento, sobretudo econômico. Nosso referencial teórico conta com autores nacionais e estrangeiros dedicados ao estudo tema, a exemplo de Carlos Alberto Bittar, António Menezes Cordeiro, David de Oliveira Festas, Capelo de Sousa, entre outros.

Não temos a pretensão de esgotar a matéria, caracterizada, ademais, por um dinamismo particular; tampouco buscamos por respostas definitivas. Isso porque, na Ciência 
do Direito, como adverte Larenz (1983, p. 203), "é-nos, em todo caso, lícito acreditar que nos chega à mão, aqui e ali, um pedaço do fio cujo fim é para nós oculto".

\section{RELEVÂNCIA E LIMITES DO CONSENTIMENTO NO APROVEITAMENTO DOS DIREITOS DA PERSONALIDADE}

O consentimento é a forma através da qual se dá o aproveitamento, sobretudo econômico, dos direitos da personalidade, em homenagem à sua dimensão positiva (BITTAR, 2009) ${ }^{3}$.

O titular do direito, em razão da autodeterminação que incide sobre os bens que integram sua personalidade, pode, observadas certas limitações impostas, em geral, a todos os negócios jurídicos, consentir com o aproveitamento de seus direitos da personalidade, como comumente ocorre com a imagem, a voz e, mais recentemente, a privacidade e a intimidade.

Algumas considerações, contudo, são importantes quando se coloca em causa o aproveitamento econômico dos direitos da personalidade.

A primeira delas diz respeito à natureza jurídica do consentimento exigido do titular no aproveitamento econômico dos seus direitos da personalidade. Ao nosso sentir, não se revela adequada a dissociação entre valores pessoais e patrimoniais dos direitos da personalidade, especialmente porque tem como fundamento o mesmo bem e visam à promoção dos mesmos valores.

Logo, o consentimento prestado pelo titular visando o seu aproveitamento é uma forma de exercício do direito privado da personalidade, na sua dimensão positiva. Neste sentido, o consentimento é resultado da autodeterminação do indivíduo sobre os bens que integram sua personalidade, cabendo a si próprio decidir como, se e em que condições pretende explorá-los (FESTAS, 2009).

O consentimento permite o aproveitamento econômico dos direitos da personalidade, revestindo-se, na maioria das vezes, sob a forma de negócio jurídico. Dada a natureza e ao fundamento ético dos direitos da personalidade, o consentimento não pode ir de encontro à

\footnotetext{
${ }^{3} \mathrm{O}$ autor destaca a circulação dos valores componentes da personalidade, registra que "premissa fundamental de qualquer utilização pública é a autorização expressa do titular e por via de contratos adequados, para que, previamente, possa eleger os modos pelos quais aparecerá perante o público. Esses mecanismos - unidos ao sistema sancionatório exposto - permitem garantir ao titular, de outra parte, a remuneração correspondente ao uso ajustado, evitando, ademais, que estranhos possam, sem título jurídico próprio, ingressar no respectivo circuito, daí auferindo proventos econômicos”. (BITTAR, 2009. p. 231).
} 
proteção dos valores pessoais. O aproveitamento manifestamente vexatório, contrário à moral, aos bons costumes ou à ordem pública não pode ser admitido.

A venda de órgãos ou partes do corpo humano, por exemplo, encontra obstáculos em vedação legal e, assim não fosse, ofenderia a moral coletiva. A cessão do direito à imagem que implique, v.g., em excessiva limitação à liberdade pessoal é igualmente nula por ser contrária às normas de ordem pública.

Festas (2009), ao tratar do aproveitamento econômico do direito à imagem, ensina que, no Direito Português, o "art. 81\%1 determina, em termos genéricos, que toda a limitação voluntária ao exercício dos direitos da personalidade é nula quando seja contrária aos princípios da ordem pública" (2009, p. 318).

Sousa (1995, p. 448), por sua vez, destaca:

[...] o Código Civil português admite limitações voluntárias ao exercício dos direitos de personalidade, apontando como ressalva a não-contrariedade à ordem pública, e desde que o consentimento não seja contrário à lei ou aos bons costumes".

Para o mesmo autor, "tais restrições voluntárias do exercício dos direitos da personalidade podem revestir o caráter de negócio jurídico e, quando válidas, os respectivos efeitos produzem-se entre as partes" (SOUSA, 1995, p. 448).

Os negócios jurídicos que tenham por objeto direitos da personalidade devem, outrossim, guardar consonância com os demais requisitos de validade previstos na legislação, conforme ocorre com a generalidade dos negócios. No caso do Brasil, previstos, genericamente, no art. 104 do Código Civil de 2002. (BRASIL, 2002).

Ainda quanto ao consentimento, a doutrina portuguesa, atenta aos efeitos produzidos pela limitação voluntária dos direitos da personalidade, distingue três modalidades. São eles: o consentimento tolerante, o consentimento autorizante e o consentimento vinculante.

De acordo com Sousa, o consentimento tolerante tem natureza de ato jurídico unilateral, sem caráter vinculativo. Nele o titular do direito, antes de qualquer agressão à sua personalidade, exclui a ilicitude da violação ao seu bem da personalidade. Trata-se de exclusão pontual e fatual da ilicitude, não constituindo uma relação vinculativa. $\mathrm{O}$ efeito do consentimento, neste caso, é o de afastar a ilicitude específica, não decorrendo qualquer poder ou direito de agressão. (SOUSA, 1995). 
Segundo Sousa ${ }^{4}$ (1995, p. 441-442).

O consentimento tolerante do lesado é meramente integrativo, não criando ou constituindo qualquer direito para o agente, é unilateral, anterior à lesão e, nos termos dos n. 1 e 2 do art. 340 do Código Civil [português], torna lícito o ato lesivo dos direitos de personalidade do lesado, a não ser que esse ato lesivo seja contrário a uma proibição legal ou aos bons costumes, o que tem lugar quando estejam em causa bens da personalidade particularmente relevantes.

Já o consentimento autorizante tem eficácia constitutiva, resultando dele um poder jurídico de agressão ou de lesão. Conforme Sousa (1995):

O consentimento autorizante só é válido se não for contrário aos princípios da ordem pública, insere-se normalmente num negócio ou ato jurídico de estrutura bilateral e tem um caráter constitutivo, pois envolve a celebração de um compromisso jurídico sui generis, pelo qual o titular de direitos de personalidade limita voluntariamente o exercício de tais direitos, mas dispõe sempre da faculdade de revogar tal consentimento, ainda que com a obrigação de indenizar os prejuízos causados às legítimas expectativas da outra parte (SOUSA, 1995, p. 441-442).

Contudo, o consentimento autorizante não constitui no titular qualquer vinculação, de sorte que o poder de agressão conferido a terceiro é revogável a qualquer tempo, sem prejuízo de eventual indenização decorrente da frustração das legítimas expectativas (FESTAS, 2009).

Por sua vez, o consentimento vinculante, como a terminologia sugere, é aquele caracterizado como verdadeiro negócio jurídico, revelando, portanto, uma limitação voluntária aos direitos da personalidade. Para Capelo de Sousa, estando em causa um compromisso vinculante, o titular encontra-se verdadeiramente obrigado ao cumprimento, ainda que, atendendo aos bens em causa, a vinculação se encontre sujeita a um regime especial (SOUSA, 1995).

Conforme aponta Festas (2009),

[...] o consentimento vinculante é, nos termos gerais dos negócios jurídicos (arts. $230^{\circ}$ e ss. e $406^{\circ}$ ), unilateralmente irrevogável, gerando o incumprimento da obrigação decorrente do consentimento vinculante uma obrigação de indemnizar pelo interesse contratual positivo". (2009, p. 324).

\footnotetext{
${ }^{4}$ [...] "os direitos da personalidade podem ser revestidos daquele particular e mais modesto aspecto da faculdade de disposição, que é constituído pela faculdade de consentir na lesão: quando se diz que eles são indisponíveis, desprovidos da faculdade de disposição, a expressão deve ser entendida nestes termos". (DE CUPIS, 2004. p. $64)$.
} 
A tripartição proposta por Souza evidencia que a irrenunciabilidade e a intransmissibilidade não são incompatíveis com o aproveitamento dos direitos da personalidade, que, à luz da sua construção, dar-se-á nas modalidades autorizante e vinculante. Na primeira - autorizante - o consentimento revela-se precário, podendo o titular do direito desvincular-se a qualquer tempo. No segundo - vinculante - o titular do direito, prestado o consentimento, vincula-se ao aproveitamento de seu direito da personalidade (SOUSA, 1995).

Neste cenário, é possível verificar que o consentimento não é incompatível com o aproveitamento dos direitos da personalidade, notadamente quando se analisa a sua dimensão positiva (BRUGUIERE, 2006).

As limitações voluntárias aos direitos da personalidade, desde que compatíveis com as normas de ordem pública ${ }^{5}$ (CORDEIRO, 2004) com a moral e os bons costumes, são fruto, na verdade, da autodeterminação do sujeito sobre aqueles bens que integram a sua personalidade. Trata-se, em outras palavras, de manifestação da própria personalidade.

Vê-se, assim, que o consentimento, desde que delimitado quanto ao objeto, não equivale à renúncia, à transmissão ou disposição de direitos. O consentimento, no tocante ao aproveitamento dos direitos da personalidade, evidencia a dimensão positiva desses direitos, em homenagem à autodeterminação do sujeito.

Segundo ensina Festas (2009):

[...] assente o objecto do consentimento, considerado nas suas diferentes perspectivas, deve ser determinado ou ser, pelo menos determinável (art. 280.\%1). E prossegue, parece-nos inadmissível um consentimento ilimitado, equivalente, em termos práticos, a uma renúncia ao direito [...]. A delimitação do objecto e conteúdo do consentimento pode ser realizada de diversas formas, nomeadamente do ponto de vista temporal, espacial e ainda quanto aos actos que poderão ser praticados [...] (2009, p. 326-327).

\footnotetext{
${ }^{5}$ A propósito, Cordeiro destaca que "o artigo 81.\% [do Código Civil Português] consignou uma regra de nãocontrariedade aos princípios da ordem pública, com alguma ênfase. Provavelmente impôs-se, aí, uma preocupação "ordeira" do Estado Novo, mais do que uma referência dogmática útil. De facto, os negócios que envolvam direitos de personalidade devem respeitar os vectores injuntivos do ordenamento, a que se chama "ordem pública". Admitimos que ela possa, aqui, ser particularmente exigente. Mas há que se respeitar, ainda, os demais requisitos do artigo $2800^{\circ}$, com relevo para a determinabilidade e a não contrariedade aos bons costumes. Resulta do primeiro desses requisitos que qualquer limitação aos direitos de personalidade deve ser clara e perceptível, sob pena de poder assumir proporções com que o sujeito não pudesse contar. Quanto aos bons costumes: ficam sempre ressalvados os códigos éticos que, nesse domínio, são exigentes e as regras de conduta sexual e familiar próprias da nossa sociedade. O Direito não dá os seus instrumentos para sancionar condutas que se colocam à margem, por liberal que seja o modo de pensar dos civilistas". (CORDEIRO, 2004. v. 3. p. 117).
} 
Em assim sendo, cabe ao titular do direito, ao consentir com o aproveitamento dos bens que integram a sua personalidade ${ }^{6}$, definir os limites, a forma, o prazo e o conteúdo dessa exploração ${ }^{7}$, devendo haver interferência judicial naqueles casos em que houver, repetimos, ofensa à ordem pública, à moral ou aos bons costumes, como, de regra, já ocorre nos demais negócios jurídicos que têm por objeto bens diversos ${ }^{8}$.

É neste sentido a lição de Bittar (2009, p. 232), segundo o qual:

[...] os contratos devem especificar a finalidade, as condições de uso, o tempo, o prazo e as demais circunstâncias que compõem o conteúdo do negócio, interpretando-se restritivamente, ou seja, permanecendo no patrimônio do licenciante outros usos não enunciados por expresso.

\section{Ainda segundo Bittar:}

[...] constituem ilícitos não só os usos não consentidos, como também os que extrapolem aos limites - de meio, de fim, de prazo, ou qualquer outro previstos no contrato (como na utilização de imagem de atriz ou de cena, no cinema ou no teatro, ou em outro meio, obtida por meio de fotografia, ou de outro processo de reprodução; no uso de imagem de pessoa, permitida para a campanha de um produto, em outro; na utilização de reprodução da efígie de alguém, autorizada para fim científico, em fim comercial; no uso, em revista

\footnotetext{
${ }^{6}$ A propósito, sobre a importância do consentimento no tocante aos limites do aproveitamento dos direitos da personalidade, o acórdão RLx n. ${ }^{\circ}$ 1086/2003-7, de 28.9.2004, Neste caso, o Tribunal da Relação de Lisboa TRL, reconheceu uma autorização tácita ao uso da imagem do autor da ação na capa de um álbum musical, mas considerou que o uso da respectiva imagem em cartazes afixados em lugares públicos teria extrapolado os limites da autorização concedida: "Em conclusão: a dita ampliação das aludidas fotografias do autor/apelado, por parte da apelante, para cartazes, sem o prévio consentimento, por qualquer forma, daquele, sendo afixadas nos locais públicos já indicados, visando beneficiar de publicidade e promoção gratuitas, traduziu-se, portanto, numa acção ilícita, dado que, nessas circunstâncias, violou o direito à imagem daquele, em especial e designadamente, a salvaguarda do direito de personalidade do mesmo, daí decorrendo, a seu favor, o direito a uma indemnização, não podendo deixar de atender-se, para este efeito, à especificidade e natureza da sua actividade profissional, com todos os efeitos que, necessariamente, ela comporta." (PORTUGAL, 2004, online).

${ }^{7}$ É neste sentido a lição de Carlos Alberto Bittar, segundo o qual "os contratos devem especificar a finalidade, as condições de uso, o tempo, o prazo e as demais circunstâncias que compõem o conteúdo do negócio, interpretando-se restritivamente, ou seja, permanecendo no patrimônio do licenciante outros usos não enunciados por expresso. Ainda segundo Bittar, [...] constituem ilícitos não só os usos não consentidos, como também os que extrapolem aos limites - de meio, de fim, de prazo, ou qualquer outro - previstos no contrato (como na utilização de imagem de atriz ou de cena, no cinema ou no teatro, ou em outro meio, obtida por meio de fotografia, ou de outro processo de reprodução; no uso de imagem de pessoa, permitida para a campanha de um produto, em outro; na utilização de reprodução da efígie de alguém, autorizada para fim científico, em fim comercial; no uso, em revista comercial, de retrato pintado de uma pessoa, e outros tantos)". (BITTAR, 2009, p. 232).

${ }^{8}$ Romain Ollard, a propósito, destaca que, dada a sua dupla dimensão, os contratos que têm por objeto bens que integram a personalidade devem ser estritamente delimitados quanto à forma, modo, prazo e espaço de exploração. Segundo Ollard, des contrats d'exploitation (...) exige que "l'objet des contrats d'exploitation des biens de la personnalité soit strictement delimite. Ele pose ainsi une exigence de précision, dans la rédaction des contrats, tant en ce qui concerne leur durée, leur territorialité ou leur destination - principe de précision - qu'en ce qui concerne le mode d'exploitation autorisé - principe de spécialité”. (OLLARD, 2013. p. 354). No mesmo sentido na obra de Marino, L. Traité de droit de la presse et des médias. LexisNexis-Litec, n. 1774, 2009. (MARINO, 2009, p. 321).
} 
comercial, de retrato pintado de uma pessoa, e outros tantos)". (BITTAR, 2009, p. 232).

É importante ressaltar, contudo, que, nos negócios jurídicos que têm por objeto direitos da personalidade, o consentimento assume especial relevância. Isso ocorre porque os direitos da personalidade possuem conteúdo complexo: revelam aspectos morais e patrimoniais. Assim, a despeito de o aproveitamento, até mesmo econômico, ser compatível com os direitos privados da personalidade, é preciso que o conteúdo ético seja preservado, sob pena de indesejável dissociação dos aspectos morais e patrimoniais, deixando de conferir a proteção necessária à pessoa.

No caso dos direitos da personalidade, os limites devem ser ainda mais rigorosos a fim de não se perder de vista o fundamento ético que permeia esses direitos. É neste sentido que, apesar do consentimento prestado pelo titular, certas manifestações de vontade não podem ser consideradas válidas quando colidirem com o conteúdo ético dos direitos da personalidade.

Além disso, é oportuno destacar que a interpretação dos negócios jurídicos que tenham por objeto bens da personalidade deve ser restritiva, de modo que a autorização de aproveitamento alcance apenas aquilo que foi expressamente ajustado ${ }^{9}$. Eventuais cláusulas dúbias ou contraditórias devem ser interpretadas à luz do fundamento ético dos direitos da personalidade.

A autonomia privada, além dos limites comumente invocados, deve ser, portanto, exercida em consonância com a dupla dimensão dos direitos da personalidade. É preciso, portanto, que as dimensões moral e patrimonial coexistam a fim de que o conteúdo ético dos direitos da personalidade seja preservado.

Nesta esteira, por vezes, o consentimento prestado pelo titular do direito, a despeito de esclarecido e limitado quanto ao objeto e ao tempo, pode não ser considerado válido por conflitar com o conteúdo ético que permeia todo e qualquer direito da personalidade.

O emblemático caso do anão que era atirado em uma casa noturna de um lado a outro ilustra bem os limites da autonomia privada em matéria de direito da personalidade. Por mais que os direitos da personalidade sejam compatíveis com o aproveitamento econômico, não se

\footnotetext{
${ }^{9}$ Neste sentido, cf. LOPES, Cláudia Possi. Limitações aos direitos de autor e de imagem. Revista da Associação Brasileira da Propriedade Intelectual, São Paulo, n. ${ }^{\text {o } 35, ~ 1998 . ~(L O P E S, ~ 1998, ~ p . ~ 15) . ~}$
} 
deve ignorar o seu conteúdo ético, que, ademais, encontra fundamento em limitações morais e sociais necessárias ao bom convívio.

Sobre os limites da autonomia privada nos negócios que tenham por objeto direitos da personalidade, destaca Resta (2007):

[...] qualquer negócio que tenha por objeto atributos de pessoa estará sujeito ao cumprimento dos limites de compatibilidade com a ordem pública e a moral (cláusulas gerais a concretizar à luz do preceito mais específico de proteção da dignidade humana) e não pode cumprir validamente qualquer fenômeno de alienação das situações envolvidas. (2007. p. 1066) - tradução nossa.

Não bastasse, o exercício dos direitos da personalidade, assim como ocorre com a generalidade das relações jurídicas, não pode se dar em desconformidade com os limites impostos pela boa-fé e por função socioeconômica. Neste sentido, Sousa (1995) destaca:

Correspondendo também os direitos da personalidade a interesses ou fins jurídicos, não só o seu titular no respectivo exercício não poderá, como vimos, exceder os limites impostos pelo fim social ou econômico desses direitos, como também o próprio valor relativo de um concreto modo de exercício de um direito da personalidade subjectivado conflitual depende, em certa medida, das consequências objectivas dele decorrentes, da natureza e da intensidade dos interesses ou fins efectivamente prosseguidos pelo respectivo titular e do posicionamento de tais consequências objectivas e interesses ou fins subjectivos na hierarquia dos interesses ou fins juridicamente tutelados por tal direito. (SOUSA, 1995, p. 535).

Não há dúvidas de que a autonomia privada é compatível com o exercício dos direitos privados da personalidade. Tarefa das mais difíceis, contudo, é encontrar o ponto de equilíbrio entre as dimensões moral e patrimonial dos direitos da personalidade.

Diariamente, programas de televisão, por exemplo, exploram, com o consentimento do titular do direito, situações manifestamente constrangedoras. Nestes casos, a despeito do constrangimento, o consentimento tem sido, em regra, admitido, fundado na autonomia privada, cabendo, assim, ao titular do direito da personalidade definir o modo e a forma de exploração. A propósito, a lição de Vasconcelos ${ }^{10}$ (2006), segundo o qual:

\footnotetext{
10 "E acrescenta a referência à ordem pública, no artigo $81^{\circ}, \mathrm{n}^{\circ} 1$ do Código Civil, exprime a dualidade atrás enunciada entre o que é disponível nos direitos de personalidade e o que não é. Os mais importantes valores da personalidade são indisponíveis. A vida não pode ser trocada por dinheiro, nem é lícito o suicídio. Mas já é lícito que as pessoas se submetam voluntariamente a experiências médicas ou científicas das quais possa resultar perigo para a vida. E soa mesmo muito valiosamente consideradas práticas voluntárias em que a vida é posta em perigo, por exemplo, por membros das forças armadas ou das forças de segurança, de serviços de salvamento, ou
} 
Reprováveis e ilícitas nos parecem já outras práticas que se traduzem no aviltamento público da dignidade de pessoas em meios de comunicação social, normalmente na televisão, nos chamados 'reality shows', como modo de obtenção de lucro e de ganho económico. É duvidoso que o simples consenso e ganância material, na ausência de outros valores, seja suficiente para fundar a licitude das ofensas à dignidade necessariamente envolvidas. (2006, p. 165).

A autonomia privada, em matéria de direito da personalidade, deve ser a regra e apenas em casos excepcionais deve haver a intervenção estatal, sob pena, reiteramos, de suprimir, de modo injustificado, a autodeterminação da pessoa sobre o seu modo de ser físico e moral.

A evolução dos costumes e diversos aspectos sociais contribuem para a apreciação dos limites da autonomia privada no exercício dos direitos da personalidade. Não nos parece possível, porém, estabelecer limites rígidos e atemporais. Contudo, é preciso que o conteúdo ético dos direitos da personalidade seja sempre preservado, sob pena de conduzir-se a odiosa dissociação entre as dimensões moral e patrimonial.

Neste cenário, não se pode ignorar a especial relevância do consentimento, sobretudo diante da inafastável tutela da dignidade da pessoa e dos seus atributos, que não pode ceder a interesses econômicos, ainda que relevantes. A vontade tem, portanto, especial importância, revelando-se, quando livre e esclarecida, instrumento eficaz na prevenção e gestão de conflitos decorrentes do aproveitamento econômico dos direitos da personalidade.

Ainda de acordo com Vasconcelos (2006):

[...] acrescenta a referência à ordem pública, no artigo $81^{\circ}, \mathrm{n}^{\circ} 1$ do Código Civil, exprime a dualidade atrás enunciada entre o que é disponível nos direitos de personalidade e o que não é. Os mais importantes valores da personalidade são indisponíveis. A vida não pode ser trocada por dinheiro, nem é lícito o suicídio. Mas já é lícito que as pessoas se submetam voluntariamente a experiências médicas ou científicas das quais possa resultar perigo para a vida. E soa mesmo muito valiosamente consideradas práticas voluntárias em que a vida é posta em perigo, por exemplo, por membros das forças armadas ou das forças de segurança, de serviços de salvamento, ou mesmo por médicos e outros intervenientes no tratamento de doenças contagiosas" (2006, p. 155).

mesmo por médicos e outros intervenientes no tratamento de doenças contagiosas" (VASCONCELOS, 2006, p. 155). 


\section{O PAPEL DO CONSENTIMENTO NO APROVEITAMENTO DOS DIREITOS DA PERSONALIDADE}

O aproveitamento econômico dos direitos da personalidade, na maioria das vezes, reveste-se da forma de negócio jurídico. Os contratos de cessão de imagem, de voz, de exibição de detalhes da vida íntima e privada, as autorizações consentidas em esportes radicais, que conduzem, no mais das vezes, a lesões físicas, são exemplos de negócios jurídicos bilaterais. Não se pode ignorar, ainda, que alguns bens da personalidade revelam projeção patrimonial pos mortem, transmitindo aos sucessores o direito de explorarem economicamente e com exclusividade os atributos que integraram a personalidade do falecido $^{11}$.

Por vezes, a inação do titular do direito, que deixa de tomar as providências necessárias à cessação da ameaça ou da lesão, embora não se revista da forma de negócio jurídico, pode implicar aproveitamento econômico dos direitos da personalidade.

Pensemos, por exemplo, nas biografias não autorizadas. A divulgação, por terceira pessoa, de biografia de outra, sem a devida autorização, pode levar o titular dos direitos revelados a tentar impedir a divulgação ou, por outro lado, consentir, tacitamente, com a

\footnotetext{
${ }^{11}$ Violação de direito à imagem de pessoa falecida, no sentido imagem-retrato, ocorreu na captação da imagem mortuária do pintor Di Cavalcanti quando exposta no Museu de Arte Moderna do Rio de Janeiro. A obra cinematográfica de autoria de Glauber Rocha permanece inédita por decisão judicial que decidiu pela interdição, a pedido dos herdeiros do famoso pintor. É verdade que a situação retratada diz respeito à violação (agressão) do direito à imagem da pessoa falecida. Porém, é possível aferir a dimensão patrimonial dos direitos da personalidade e o seu aproveitamento pelos herdeiros do falecido. (Regina Sahm. Direito à imagem no Direito Civil contemporâneo: de acordo com o novo Código Civil - Lei no 10.406, de 10-1-2002. São Paulo: Atlas, 2002 . p. 241). Ainda sobre o caso "Di Glauber", esclarece Antônio Carlos Morato: "Glauber Rocha finalizou seu filme, e no ano seguinte foi premiado no Festival de Cannes, cujo júri era presidido pelo cineasta Roberto Rosselini, amigo de Di Cavalcanti. /A exibição do filme foi interditada pela justiça desde 1979, quando da conceção de liminar pela $7^{\mathrm{a}}$ Vara Cível, ao mandado de segurança impetrado pela filha do pintor, Elizabeth Di Cavalcanti. / De acordo com uma reportagem publicada no jornal O Globo do dia 12 de junho de 1979, dia seguinte à proibição, Di chegou a passar nas sessões das $14 \mathrm{~h}$ e $16 \mathrm{~h}$ em alguns cinemas da cidade. Mas às $18 \mathrm{~h}, \mathrm{o}$ oficial de Justiça Walter Coelho Fanti e o advogado de Elizabeth Di Cavalcanti, Eduardo Mattar, chegaram ao cinema Rio Sul, onde haveria projeção com a presença de Glauber e convidados. As latas com o filme foram lacradas e recolhidas ao Museu da Imagem e do Som. / Chegou a ser exibido duas vezes na televisão, na TVE do Rio, antes de sua proibição, e na Bandeirantes, num especial sobre o diretor, que foi ao ar depois de sua morte. / Mais de 20 anos depois de ter sua exibição proibida através de uma liminar, o filme pode voltar a ser exibido. Não porque tenha sido liberado, enfim, pela Justiça. Mas simplesmente porque nunca esteve legalmente impedido. O advogado José Mauro Gnaspini defendeu uma tese de mestrado sobre direito autoral na Escola de Comunicação e Artes da Universidade de São Paulo. Segundo Gnaspini - que reconstituiu a ação a partir de fragmentos espalhados por escritórios de advocacia do Rio, pois o processo havia desaparecido do Arquivo Público da cidade - não existem fundamentos jurídicos para a interdição e o filme pode ser liberado, imediatamente, para exibições. / O filme nunca chegou realmente a ser proibido. A ação ocorreu só contra a Embrafilme. Glauber, que tinha direito inalienável sobre a obra, não sofreu um processo". (MORATO, 2011/2012, p. 146).
} 
publicação, na certeza de que lhe trará mais benefícios, até mesmo patrimoniais, do que prejuízos.

Pensemos, agora, na divulgação de conteúdo em mídias sociais ou outras plataformas na internet. O vídeo publicado sem autorização da pessoa pode causar-lhe danos ou, ao contrário, trazer-lhe fama, ainda que temporária, tornando-a conhecida do grande público, permitindo que possa, diante desse novo cenário, explorar economicamente seus atributos da personalidade. Exemplos como este não são incomuns, especialmente nos dias atuais em que as redes e mídias sociais apresentam destacado alcance.

O consentimento, no tocante ao aproveitamento dos direitos da personalidade, pode revestir-se de variadas formas. As hipóteses, contudo, em que o consentimento é revestido da forma de negócio jurídico bilateral são mais comuns e dela nos ocuparemos nas linhas seguintes.

A primeira questão que deve ser analisada diz respeito à eficácia dos poderes de aproveitamento econômico dos bens da personalidade cedidos pelo titular à terceira pessoa. Em linhas gerais, a questão assim se apresenta: o titular do direito pode conceder a outra pessoa poderes de aproveitamento econômico dos seus bens da personalidade que gozem de eficácia erga omnes?

Pensemos na situação em que determinado modelo fotográfico celebrou contrato com uma grande loja de varejo por meio do qual consentiu que sua imagem fosse utilizada, com exclusividade neste gênero, por 2 (dois) anos, em comerciais na imprensa falada e escrita, em mídias diversas (rádio, televisão e internet). Durante a vigência do contrato, o modelo fotográfico, por conta dos limites do consentimento prestado, não poderá emprestar sua imagem a qualquer outra campanha publicitária, do mesmo gênero. Caso a imagem desse modelo fotográfico venha a ser utilizada, sem autorização, por terceira pessoa, dedicada igualmente ao ramo de varejo, pode o contratante agir em nome do titular do direito da personalidade, impedindo, assim, a divulgação? Em outras palavras: o consentimento implica atuação perante terceiros, com clara eficácia erga omnes?

É oportuno registar que nos limitamos aqui a questionar o aproveitamento dos direitos da personalidade. É evidente que há outros instrumentos normativos aptos a fazer cessar a divulgação não autorizada, notadamente à luz do Direito Concorrencial. Contudo, sem a pretensão de esgotar o tema, cuidaremos apenas do aproveitamento dos bens da 
personalidade e do consentimento prestado pelo titular do direito visando à exploração desses bens, atentos à identificação de mecanismos eficazes de prevenção e gestão de conflitos.

Na espécie, não há dúvidas de que o titular do direito pode se opor à divulgação não consentida, ainda que esta não lhe acarrete qualquer dano. A sua oposição pode estar pautada, inclusive, em dever contratual, voluntariamente assumido.

Por outro lado, caso não haja previsão contratual que obrigue o titular do direito a impedir a divulgação não autorizada de sua imagem, pode o outro contratante impedi-la, mesmo tratando-se de um direito da personalidade?

É preciso reiterar que os direitos da personalidade, apesar de compatíveis, em alguns casos, com o aproveitamento econômico, são intransmissíveis e inalienáveis. Considera-se nulo o consentimento prestado pelo titular do direito que implique em verdadeira renúncia, disposição ou alienação.

A questão relativa à transmissão inter vivos dos direitos da personalidade é, contudo, polêmica. Forkel, citado por Festas ${ }^{12}$, atento às particularidades do Direito Germânico, sustenta que a eficácia meramente inter partes fragiliza o aproveitamento econômico dos direitos da personalidade, deixando uma das partes em situação desfavorecida. Assim, propõe uma teoria de transmissão limitada dos direitos da personalidade. Segundo essa teoria, o consentimento não implica transmissão absoluta e completa do direito da personalidade. Contudo, uma parte desse direito é separada e transmitida ao contratante, que adquire um direito-filho. O direito-mãe continua em poder do titular do bem da personalidade e a transmissão tem por objeto apenas parte desse direito, chamado por Forkel de direito-filho de acordo com Festas (2009):

[...] na designada transmissão limitada (vinculada), enquanto existe o direitofilho, mantém-se a vinculação (que pode ter diferentes medidas) entre o direito-mãe e o direito-filho. Nestes termos, continuam a ser protegidos diversos interesses do transmitente e o poder pertence ainda, na raiz, ao titular do direito-mãe. Isto apesar de o titular do direito-mãe o ter onerado com o direito-filho e, portanto, já não o deter integralmente nas suas mãos. A medida de proteção dos 'interesses' do transmitente e do adquirente resultará da estipulação das partes, salvo disposição legal imperativa regulando a matéria (2009, p. 339- 340).

\footnotetext{
12 [...] "na designada transmissão limitada (vinculada), enquanto existe o direito-filho, mantém-se a vinculação (que pode ter diferentes medidas) entre o direito-mãe e o direito-filho. Nestes termos, continuam a ser protegidos diversos interesses do transmitente e o poder pertence ainda, na raiz, ao titular do direito-mãe. Isto apesar de o titular do direito-mãe o ter onerado com o direito-filho e, portanto, já não o deter integralmente nas suas mãos. A medida de protecção dos 'interesses' do transmitente e do adquirente resultará da estipulação das partes, salvo disposição legal imperativa regulando a matéria”. (FESTAS, 2009, p. 339-. 340).
} 
$\mathrm{Na}$ teoria desenvolvida por Forkel, o indivíduo não perde o controle sobre o conteúdo pessoal do direito da personalidade. Por outro lado, concede-se mais proteção ao adquirente do direito, que, quanto ao direito-filho cedido e aos seus aspectos patrimoniais, pode agir contra terceiros, havendo, portanto, verdadeira oponibilidade erga omnes.

Em Portugal, a questão relativa à transmissibilidade dos direitos da personalidade é objeto de profundo debate. Os casos Panini ${ }^{13} e$ Velli ${ }^{14}$ foram, na jurisprudência portuguesa, precursores no que diz respeito a esta temática.

13 "No caso Panini, a Panini Portugal Editores Ltda. havia obtido autorização da Federação Portuguesa de Futebol para negociar diretamente com o Sindicato de Jogadores Profissionais de Futebol a edição de um álbum da seleção nacional e dos retratos dos jogadores. Assim, a Panini celebrou contrato de cessão de direito com o Sindicato, resultando o direito exclusivo à reprodução e utilização da imagem dos jogadores no álbum a ser editado. A Mabilgráfica-estudos gráficos Ltda comercializou um álbum semelhante, sem qualquer autorização, usando, inclusive, a imagem de alguns jogadores que haviam autorizado o Sindicato a negociar com a Panini. Esta ingressou com ação judicial visando impedir a publicação da imagem dos jogadores pela Mabilgráfica. Em primeira instância, a Mabilgráfica foi condenada a ressarcir os danos causados à Panini, ficando, ainda, impedida de utilizar a imagem dos jogadores, sob o argumento que frustrou as legítimas expectativas de aproveitamento econômico da concorrente e valeu-se de bens da personalidade de terceiros sem o devido consentimento. Ademais, restou expressamente reconhecido que os jogadores de futebol consentiram que suas imagens fossem negociadas pelo Sindicato, que os representava, tendo a Panini, portanto, autorização para a exploração dos bens da personalidade empregados. Ocorre que o STJ, ao apreciar recurso da Mabilgráfica, entendeu que o contrato de cessão celebrado entre a Panini e o Sindicato era nulo de pleno de direito. Segundo o STJ, o Sindicato não está autorizado a negociar direitos da personalidade de terceiros, que são, por natureza, intransmissíveis. Para o STJ, o Sindicato negociou os direitos de imagem dos jogadores como se os houvesse recebido por transmissão, o que, tratando-se de direito da personalidade, revela-se inadmissível". (FESTAS, 2009. p. 344-345).

14 "No caso Velli, a autora da ação era uma sociedade dedicada à representação e exploração da imagem de desportistas e era a legítima e exclusiva representante do jogador profissional de futebol Velli. A autora negociou com o jogador de futebol a cessão de seu direito de imagem, que poderia ser por ela explorado ou por terceiros. $\mathrm{O}$ jogador de futebol celebra, na sequência, contrato de trabalho desportivo com outra sociedade. Esta firmou com a autora, que já detinha os direitos de imagem do jogador, contrato através do qual se comprometeu a pagar certa quantia em dinheiro pelo uso da imagem de Velli. Findo o contrato do jogador de futebol com a ré, a autora promove a ação judicial visando cobrar quantia decorrente do contrato de cessão de imagem do profissional desportivo, alegadamente não paga. No caso Velli, o direito de imagem do jogador foi negociado e explorado diretamente pela sociedade autora, que, inicialmente, celebrou com ele o contrato de cessão. Em primeira instância, foi reconhecido o direito da autora à quantia reclamada, reconhecendo-se válido o contrato de cessão firmado com a sociedade ré, com a qual o jogador havia firmado contrato de trabalho. Em grau de recurso, contudo, o Tribunal, apoiado no acórdão do caso Panini, reafirmou que os direitos da personalidade são intransmissíveis e que a cessão genérica do direito à imagem, como ocorreu no contrato firmado entre a autora e o jogador de futebol, é nula de pleno de direito, revelando-se um negócio proibido pelo direito. Por fim, submetida a questão ao Supremo Tribunal de Justiça português, assentou-se que: 'Só que, na hipótese dos autos, o que está em causa não é o poder de dispor em geral da imagem da pessoa para fins comerciais, o poder de lançar no comércio todos e quaisquer retratos de que alguém, não titular do respectivo direito à imagem, disponha. O que está em causa é apenas a exploração comercial, durante um período determinado e com proveito económico para o próprio desportista, da imagem de desportista profissional de um futebolista - à qual a própria lei reconhece portanto valor económico -, por meio dos retratos, filmes, desenhos ou outras formas de exibição que, apenas nessa qualidade e durante esse período, sejam produzidos com base na sua imagem, e não no que possa respeitar a todo e qualquer aspecto da sua vida íntima e privada. Ora, não se vê em que possa ofender a ordem pública a exploração comercial dessa imagem por entidade distinta do respectivo titular, por um período de tempo limitado, permitida por lei quanto aos praticantes desportivos sem a restrição que em face do disposto no art. $^{\circ} 79^{\circ}$, n. $^{\circ} 1$, do Cód. Civil, se possa entender existir para as pessoas em geral, e livremente consentida pelo 
Apesar das dificuldades conceituais, estamos de acordo que os direitos da personalidade em si são intransmissíveis e indisponíveis. Não há que se confundir o direito com o seu exercício. O direito é indisponível e intransmissível. O exercício pode ser objeto de aproveitamento econômico por terceiros, representando a dimensão positiva dos direitos da personalidade.

Nesta ordem de ideias, todos os aspectos do aproveitamento devem ser detalhados no instrumento contratual, que poderá, inclusive, obrigar o titular do direito a promover as medidas necessárias (ou ao menos a integrar a lide, em litisconsórcio) visando afastar o uso não autorizado de seus bens da personalidade por terceiros durante a vigência do contrato.

Do mesmo modo, em homenagem ao princípio da autonomia privada, podem conferir ao cessionário (a exemplo do que ocorre com a cessão de imagem) o direito de impedir o uso do direito da personalidade objeto do contrato por terceiro não autorizado. Neste caso, o fundamento da defesa do direito da personalidade perante terceiro é o próprio ajuste de vontade.

Parece-nos, contudo, que a defesa por terceiro, nos casos em que autorizada pelo contrato, deve guardar consonância com o objeto do negócio, não podendo o cessionário opor-se a todo e qualquer ofensa aos direitos da personalidade do cedente, sob pena de se operar verdadeira disposição, ainda que temporária.

Em outras palavras: o titular do direito da personalidade objeto do negócio jurídico pode, mediante cláusula expressa, autorizar o cessionário a impedir o uso do bem da personalidade por terceiro não autorizado. Contudo, a defesa perante terceiros deve guardar consonância com o próprio contrato.

É o exemplo daquele artista que cede com exclusividade, por período certo e definidos os limites da exposição, sua imagem para uma campanha publicitária de uma famosa marca de roupas esportivas. Caso o empresário concorrente venha a empregar a imagem desse mesmo artista, sem a sua autorização, em campanha publicitária visando a promover seus produtos e serviços, pensamos que o legítimo cessionário ou licenciado pode

titular do direito à imagem, que, sem deixar de ser titular desse direito, sem a ele renunciar por meio da cedência em causa, consegue, mediante o recurso directo ou indirecto a tal exploração ou por cedência remunerada, a terceiros, da mesma, extrair rendimentos dela aproveitando a notoriedade que com o tempo e o esforço que dedique à actividade desportiva que pratique consiga alcançar.' Reiterou-se que a intransmissibilidade e indisponibilidade dos direitos da personalidade não são incompatíveis com o seu aproveitamento, desde que não impliquem em cessão do próprio direito em si”. (STJ n. ${ }^{\circ}$ 05A2577, SILVA SALAZAR) (BRASIL, 2005, online). 
se opor à divulgação, uma vez guardar consonância com o próprio objeto do contrato firmado com o artista. Não poderia, por outro lado, opor-se à divulgação de um vídeo íntimo do artista contratado, ainda que manifestamente prejudicial à sua imagem, salvo especial estipulação de vontades, o que reforça, ao nosso sentir, a relevância do consentimento na prevenção e na gestão de conflitos decorrentes do aproveitamento dos direitos da personalidade.

É oportuno destacar, por outro lado, que outros instrumentos visando a tutela externa do contrato podem ser empregados nesta matéria. Assim, e sem a pretensão de fazer um estudo aprofundado sobre o tema, revela-se oportuna a referência aos princípios da função social, da boa-fé objetiva e, sobretudo, o apelo à teoria do abuso do direito.

Vê-se, uma vez mais, que o consentimento, livre, esclarecido e atento ao fundamento ético de tutela e promoção da pessoa humana, permite não só aproveitamento dos direitos da personalidade como representa importante fator de eficácia, contribuindo, assim, com a prevenção e a gestão de conflitos.

\section{CONSIDERAÇÕES FINAIS}

Os direitos da personalidade encontram disciplina e sistematização no Direito privado, que, a despeito das críticas, remanesce distinto, por motivos vários, do Direito público. É no Direito privado que os direitos da personalidade radicam a sua origem e florescem como verdadeiros direitos subjetivos.

É verdade que os direitos da personalidade foram inicialmente concebidos para defender a pessoa dos ataques do Poder Público e, mais tarde, de outros particulares. Contudo, são, em alguns casos e observadas determinadas limitações, compatíveis com o aproveitamento consentido, sobretudo econômico.

Nesta toada, não são estranhos ao Direito e à sociedade negócios jurídicos que têm por objeto direitos da personalidade, a exemplo do que ocorre com os direitos à imagem, à voz, ao nome e, mais recentemente, à privacidade. $\mathrm{O}$ aproveitamento dos direitos privados da personalidade é recente, resulta da evolução dos meios de comunicação e de captação e transmissão da voz e da imagem e, neste novo cenário, revela a importância do consentimento.

O consentimento, quando esclarecido, livre e atento ao fundamento ético que permeia a tutela e a promoção da pessoa, contribui decisivamente com a prevenção e a gestão 
dos conflitos decorrentes do aproveitamento, especialmente econômico, dos direitos da personalidade.

Como sabido, os direitos da personalidade recaem sobre o modo de ser físico e moral da pessoa, de modo que devem ser vedados negócios jurídicos que exponham o sujeito a situações degradantes, aviltantes, devendo ser afastada a validade do consentimento prestado nestes casos.

É difícil a tarefa de identificar os casos em que o consentimento será inválido, cabendo ao intérprete, com os olhos voltados para a atualidade, perquirir a preservação do fundamento ético dos direitos da personalidade.

Inegável, contudo, a importância do consentimento, que permite, quando em consonância com as limitações que lhe são inerentes, o adequado aproveitamento dos direitos da personalidade, permitindo, ademais, a prevenção e a gestão de conflitos.

\section{REFERÊNCIAS}

BITTAR, Carlos Alberto. Teoria geral do direito civil. $2^{\mathrm{a}}$ ed. São Paulo: Forense Universitária, 2009.

BRASIL. Lei $n^{\circ}$ 10.406, de 10 de janeiro de 2002. Institui o Código Civil, Presidência da República, Brasília, DF, 2002. Disponível em:

http://www.planalto.gov.br/ccivil_03/leis/2002/lompilada.htm. Acesso em: 06 maio 2021.

BRASIL. Supremo Tribunal de Justiça - STF. Proc. $n .^{\circ}$ 05A2577, Contrato de exploração direito à imagem, Relator: Silva Salazar, Data do Acordão: 25/10/2005. Disponível em:

http://www.dgsi.pt/jstj.nsf/954f0ce6ad9dd8b980256b5f003fa814/204e20ddf82598748 02570ba006a8260?OpenDocument. Acesso em: 15 set. 2021.

BRUGUIERE, J. M. Le droit à l'image est un possible objet de contrat (et une source nouvelle de propriété incorporelle?, note ss CA Versailles, 22 sept. 2005: Légipresse, n. 231, III, no 9, 2006.

CORDEIRO, António Menezes. Tratado de direito civil português: parte geral. Coimbra: Almedina, v.3, 2004.

DE CUPIS, Adriano. Os direitos da personalidade. Campinas: Romana Jurídica, 2004. 
FESTAS, David de Oliveira. Do conteúdo patrimonial do direito a imagem: contributo para um estudo do seu aproveitamento consentido e inter vivos. Portugal: Coimbra Editora, p. 294-340, 2009.

LARENZ, Karl. Metodologia da ciência do direito. Lisboa: Fundação Calouste Gulbenkian, 1983.

LOPES, Cláudia Possi. Limitações aos direitos de autor e de imagem. Revista da Associação Brasileira da Propriedade Intelectual, São Paulo, n. ${ }^{\circ}$ 35, 1998.

MARINO, Laure. Traité de droit de la presse et des médias. LexisNexis-Litec, n. 1774, 2009.

OLLARD, Romain. Qualification de droits extrapatrimoniaux. In: SAINT-PAUL, Jean-Christophe (org). Droits de personnalité. Paris: LexisNexis, 2013.

PORTUGAL. Tribunal da Relação de Lisboa - TRL. Acórdão do processo $n .^{o}$ 1086/2003, Relator: Santo Martins, Data do acordão: 28/09/2004. Disponível em: http://www.dgsi.pt/jtrl.nsf/e6e1f17fa82712ff80257583004e3ddc/5ad18afa332d589e80 256f6c0039119e?OpenDocument. Acesso em: 16 set. 2021.

RESTA, Giorgio. Diritti della personalitá: problemi e prospettive. Millano: Giuffre, 2007.

SOUSA, Rabindranath Valentino Aleixo. Capelo de. O Direito Geral de Personalidade. Coimbra: Coimbra Editora, 1995.

VASCONCELOS, Pedro Pais. Direitos da personalidade. Almedina: Coimbra, 2006.

MORATO, Antônio Carlos. Revista da Faculdade de Direito da Universidade de São Paulo, v. 106/107, 2011/2012. 